\title{
Developmental and Condition-Related Changes in the Prefrontal Cortex Activity during Rest
}

\author{
Ling-Yin Liang1, Jia-Jin Jason Chen2 ${ }^{2}$, Patricia A. Shewokis ${ }^{3}$, Nancy Getchell ${ }^{4}$ \\ ${ }^{1}$ Department of Physical Therapy, University of Evansville, Evansville, IN, USA \\ ${ }^{2}$ Institute of Biomedical Engineering, National Cheng Kung University, Taiwan \\ ${ }^{3}$ Department of Nutrition Sciences, College of Nursing \& Health Professions \& School of Biomedical Engineering, Drexel University, \\ Philadelphia, PA, USA \\ ${ }^{4}$ Department of Kinesiology \& Applied Physiology, Biomechanics and Movement Science Program, University of Delaware, \\ Newark, DE, USA \\ Email: LL137@evansville.edu
}

How to cite this paper: Liang, L.-Y., Chen, J.-J.J., Shewokis, P.A. and Getchell, N. (2016) Developmental and Condition-Related Changes in the Prefrontal Cortex Activity during Rest. Journal of Behavioral and Brain Science, 6, 485-497.

http://dx.doi.org/10.4236/jbbs.2016.612044

Received: September 28, 2016

Accepted: October 31, 2016

Published: November 3, 2016

Copyright $\odot 2016$ by authors and Scientific Research Publishing Inc. This work is licensed under the Creative Commons Attribution International License (CC BY 4.0).

http://creativecommons.org/licenses/by/4.0/

\section{(c) (i) Open Access}

\begin{abstract}
The prefrontal cortex (PFC) plays an important role in cognitive process related to executive function, but is also active during resting states. Quantifying prefrontal cortex activity during resting states provides a baseline for interpreting task-induced brain activity. Researchers commonly use resting conditions where participants are prompted to stare at a screen (eyes open) or close their eyes (eyes closed). Are these two conditions equivalent representations of a baseline resting state? Further, does prefrontal cortex activity during these conditions change as a function of development? The aim of this study was to examine differences in prefrontal cortex activity between eyes open and eyes closed conditions during resting states in children and adults to provide a rationale of proper selection of baseline condition in future research. Thirty-six participants in 3 age groups were recruited in this study including twenty-four adults, five 12 - 15 years old children, and seven 8 - 11 years old children. Relative changes in concentrations of oxygenated hemoglobin $(\Delta \mathrm{oxy}-\mathrm{Hb})$ and deoxygenated hemoglobin ( $\Delta$ deoxy-Hb) were obtained by using functional Near-Infrared Spectroscopy (fNIRS) in eyes closed (EC) and eyes open (EO) conditions, 3 minutes each. Contrasts were tested to compare the differences of $\Delta \mathrm{oxy}-\mathrm{Hb}$ and $\Delta$ deoxy-Hb between eyes open and eyes closed conditions. The EC condition had significantly higher $\Delta$ oxy-Hb than EO when all groups were combined $(\mathrm{t}(17.268)=3.021, \mathrm{p}=.008$, Cohen's $\mathrm{d}=-0.72)$. When comparing $\Delta \mathrm{oxy}-\mathrm{Hb}$ between eyes conditions within each group, the younger group had significantly higher $\Delta$ oxy-Hb in EC than EO $(\mathrm{t}(9.459)=2.734, \mathrm{p}=0.022$, Cohen's $d=-1.46$ ). Based on these results, the EO condition may be a better baseline condition, particularly in studies with younger children, since it has less activity in the PFC that could interfere with interpretations of task-induced activity.
\end{abstract}




\section{Keywords}

Functional Near-Infrared Spectroscopy (fNIRS), Developmental Changes, Resting Conditions, Eyes Open (EO), Eyes Closed (EC)

\section{Introduction}

Researchers interested in studying developmental changes in cognitive function have a variety of brain imaging technologies from which they can chose. Given that all technologies have limitations, technological limitations can be daunting or highly unlikely to be overcome for scientists whose participant pools include children and patient populations. For example, a "gold standard" technique, functional Magnetic Resonant Imaging (fMRI), while providing excellent spatial resolution, is very expensive, and not readily transportable. Further, participants must remain still during testing as movement may result in noteworthy signal artifact-the accuracy of fMRI results is considerably affected by movement. By comparison, a relatively novel technology, functional Near Infrared Spectroscopy (fNIRS), is less expensive, easily transportable, and less sensitive to movement artifacts [1] [2] [3] [4]. This allows more movement during measurement, so participants can actually perform the tasks in more naturalistic settings. fNIRS detects hemodynamic changes induced by brain activity based on optical properties of oxygenated hemoglobin (oxy- $\mathrm{Hb}$ ) and deoxygenated hemoglobin (deoxy$\mathrm{Hb})$. Oxy-Hb and deoxy-Hb can be separated by using a few sample wavelengths based on their unique absorption coefficients at different wavelengths [5]. These characteristics make fNIRS a desirable technology for the study of cognitive development in children, particularly if tasks under study involve any movement component.

An early, essential step in using fNIRS to understand cognitive development is to determine baseline measures during a resting state from which task-related cognitive activity can be compared. Without a baseline, even the most precise measure of brain activity cannot be appropriately interpreted. Neuroimaging studies using different types of instrumentation have shown different activation patterns in diverse parts of the brain during resting states, particularly in conditions where a participant's eyes were either open or closed. In electroencephalography (EEG) studies, alpha band rhythm, which was mainly found in the posterior part of the brain, was at a higher level in the eyes closed condition when compared to the eyes open condition, indicating an increase in arousal level [6] [7]. Focal reductions were also seen in other bands (delta, theta, and beta) from eyes closed to eyes open condition. The reduction of delta and theta bands was associated with stimulus processing, indicating increased activation [8] [9]. Differences in brain activation between eyes open and eyes closed conditions were also found in studies using fMRI. In fMRI studies, greater spontaneous Blood Oxygenation Level-Dependent (BOLD) oscillations were found in eyes closed condition when compared to the eyes open condition [10]. Regarding functional connectivity, syn- 
chronous activation of spatially remote brain regions, through using fMRI, higher functional connectivity was reported in both eyes open and eyes closed conditions in different studies [6] [11] [12] [13]. Preliminary research with adults using fNIRS has also indicated that brain activity differs between the eyes open and closed conditions [14].

The sum of these studies suggests that experimental baseline conditions that do not involve mental effort such as eyes open or closed have the ability to modulate neuronal activity and local hemodynamic responses. With different activity level at baselines, these two conditions are not interchangeable. The representation of brain activity can easily have different interpretations dependent on the selected baseline condition. Meanwhile, each neuroimaging technique measures signals associated with specific physiological mechanisms and outcomes from studies using different techniques and cannot be applied interchangeably without caution [15]. Therefore, it is important to differentiate the resting brain activation patterns between eyes open and eyes closed conditions to choose an appropriate baseline condition for specific task conditions.

We are particularly interested in the prefrontal cortex (PFC). The prefrontal cortex is involved in Executive Functions (EF) which included cognitive processes such as decision making, working memory, planning, inhibition of responses, and cognitive flexibility. It also plays a key role in self-regulation and contingency-based learning [16] [17] [18]. The PFC integrates primary sensorimotor processes and modulates higherorder cognitive functions [19] [20]. The disruption of the PFC has been suggested to be the underlying reason for behavioral symptoms of mental disorders such as Autism Spectrum Disorder (ASD) [21] [22] [23]. A variety of studies have examined PFC activity during executive-related tasks such as Go/No Go tasks [24], Verbal Fluency Tests [25] [26], the Stroop task [27] [28], N-back tasks [29] [30], and a combination of the Stroop task and an N-back task [31]. An event-related activation was found in the PFC during executive-related tasks. Increased activation is expected to be accompanied with increased concentration of oxygenated-hemoglobin (oxy-Hb) and decreased concentration of deoxygenated-hemoglobin (deoxy-Hb) [32]. Thus, both oxy-Hb and deoxy-Hb were examined in current study.

The aim of current study was to compare developmental changes in PFC activation in two resting conditions (eyes open and eyes closed) among three age groups by using fNIRS as a means to determine a baseline condition that best represented "resting" state. Based on previous research, we hypothesized that concentrations of oxy- $\mathrm{Hb}$ and deoxy-Hb of the PFC would differ between eyes open and eyes closed conditions across all groups, and that these measures would change as a function of development.

\section{Method}

\subsection{Participants}

A total of 36 participants in three age groups, 8 to 11 years old (younger children), 12 to 15 years old (older children), and 20 to 35 years old (adults), participated in the study (Table 1). Participants were recruited from local universities and communities by word-of-mouth near Tainan, Taiwan. Younger children were in the 2nd to 5th grades 
Table 1. Demographic information of participants.

\begin{tabular}{cccc}
\hline & Adults & Older Children & Younger Children \\
\hline Number & 24 & 5 & 7 \\
Males/Females & $11 \mathrm{M} / 13 \mathrm{~F}$ & $1 \mathrm{M} / 4 \mathrm{~F}$ & $4 \mathrm{M} / 3 \mathrm{~F}$ \\
Age (years) & $25.89 \pm 3.08$ & $13.33 \pm 1.30$ & $9.96 \pm 1.38$ \\
Height $(\mathrm{cm})$ & $167.20 \pm 8.36$ & $153.00 \pm 13.83$ & $139.38 \pm 9.46$ \\
Weight $(\mathrm{kg})$ & $62.78 \pm 12.24$ & $42.90 \pm 15.69$ & $31.00 \pm 7.46$
\end{tabular}

and older children were in the 6th to 9th grades. All adult participants had college degrees. All participants were physically and mentally healthy, and had no family history of any kind of medical disorders. A questionnaire of exclusion criteria was given to participants or their parents to confirm that they met the inclusion criteria and did not have any of the following exclusion criteria: 1) previous head injury of any type or severity, 2) a seizure disorder, 3) open wound on the forehead, 4) unable to stay in sitting position and rest for 6 minutes, and 5) allergic to rubbing alcohol. The study was approved by the Institutional Review Board at the National Cheng Kung University. Inform consent from adult participants and parents of minor participants were obtained before the study.

\subsection{Procedures}

Data were collected in the Biosignal Lab at the National Cheng Kung University. The lights in the room were dimmed during data collection due to the requirement of the instrumentation. One 6-minute trial with 3 minutes of eyes open and 3 minutes of eyes closed was recorded for each participant. The order of conditions was randomly assigned. Participants sat in front of a monitor and rested during data collection. They were instructed to relax and stare at a cross on the screen during eyes open condition and close their eyes during eyes closed condition. A 5-second count down was given and the trial started with an auditory signal. The second auditory signal was given after 3 minutes to notify the change of eyes condition and then the final auditory signal at the end of the trial.

\section{3. fNIRS Measurements and Data Processing}

Raw light signals were acquired using a multi-channel frequency-domain fNIRS system and ISS BOXY software package (Imagent; ISS Inc., Champaign, IL). Three components of light were measured: direct current, alternative current, and the phase of the photon density wave. The wavelengths of light sources were $690 \mathrm{~nm}$ and $830 \mathrm{~nm}$. Twelve channels configured by three detectors and eight sources were recorded (Figure 1). A custom-made holding cap was placed on the forehead of participants. The interoptode distance was $3 \mathrm{~cm}$. The midpoint of middle two sources at the lower row was located roughly at the Fpz position in $10-20$ international system. This recording area 


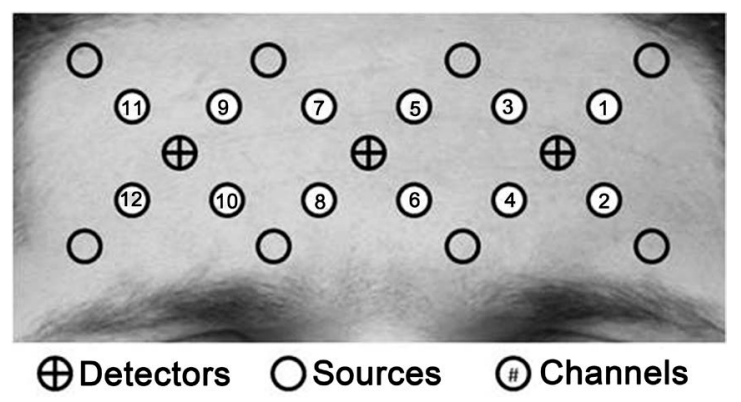

Figure 1. Location of optodes and channels.

covered bilateral superior frontal gyrus (BA 9, 10) including dorsolateral PFC and anterior PFC [33] [34]. Data were collected at a sampling rate of $12.5 \mathrm{~Hz}$.

Raw light signals were then converted into relative changes of concentration of oxy$\mathrm{Hb}(\Delta \mathrm{oxy}-\mathrm{Hb})$ and deoxy-Hb $(\Delta$ deoxy- $\mathrm{Hb})$ using the modified Beer-Lambert Law [35] [36]. A third order Butterworth band-pass filter of 0.002 to $0.5 \mathrm{~Hz}$ was applied to remove physiologically irrelevant data and equipment noise [37] [38] [39]. A principal component analysis was then performed to remove large motion artifacts [40]. The data were processed using MATLAB (Math Works, Natick, Massachusetts) and an open source software HomER ("PMI Lab-HomER",

http://www.nmr.mgh.harvard.edu/PMI/resources/homer/home.htm).

The first and the last 15 seconds of each condition were removed to prevent unstable state at the beginning of the test and the effect from previous activity [38]. The remaining 1875 data points were averaged in each channel. $Z$ scores were then calculated using mean and standard deviation of all 12 channels in each participant using

$$
Z=\frac{x-\text { mean }}{S D}
$$

Channels with extreme values ( $Z$ scores above 2 or less than 2) were removed [41]. After removed the extreme values, the average of remaining channels for each condition in each participant was calculated.

\subsection{Statistical Analysis}

Contrasts were tested for paired comparisons between eyes condition in each group and all groups combined since the data violated assumptions of normality and homogeneity. The variations of $\Delta \mathrm{oxy}-\mathrm{Hb}$ and $\Delta$ deoxy-Hb between eyes conditions in each group were examined with contrast tests as well. A Welch correction was applied for unequal variance. All data were analyzed using Statistical Package for Social Sciences (SPSS) software (version 17, SPSS, Inc, Chicago, IL, USA). The level of significance was set at 0.05 .

\section{Results}

\subsection{Overall Effect of Condition on PFC Activation}

With all groups combined, $\Delta \mathrm{oxy}-\mathrm{Hb}$ was significantly different between conditions, 
with a higher concentration in the eyes closed than eyes open condition $(\mathrm{t}(17.268)=$ 3.021, $\mathrm{p}=0.008$, Cohen's $\mathrm{d}=-0.72$ ). In contrast, there was not a difference between the two conditions in $\Delta$ deoxy-Hb with all groups combined.

\subsection{Developmental Differences}

When comparing $\Delta \mathrm{oxy}-\mathrm{Hb}$ between eye conditions in each group, only the younger children had significantly higher concentrations in the eyes closed condition ( $\mathrm{t}(9.459)$ $=2.734, \mathrm{p}=0.022$, Cohen's $\mathrm{d}=-1.46)$. There were no significant differences in $\Delta$ oxy$\mathrm{Hb}$ between eyes conditions in older children $(\mathrm{t}(6.095)=0.798, \mathrm{p}=0.455$, Cohen's $\mathrm{d}=$ $-0.50)$. In the adult group, there was a borderline significant trend $(\mathrm{t}(45.858)=1.738, \mathrm{p}$ $=0.089$, Cohen's $\mathrm{d}=-0.50)$ (Figure 2).

\section{Discussion}

The study was conducted to examine brain activity during resting states by measuring $\Delta$ oxy-Hb and $\Delta$ deoxy-Hb in the PFC in children and adults. With all groups combined, a significant difference existed between the eyes open and closed conditions, with a higher $\Delta$ oxy-Hb in the eyes closed condition.
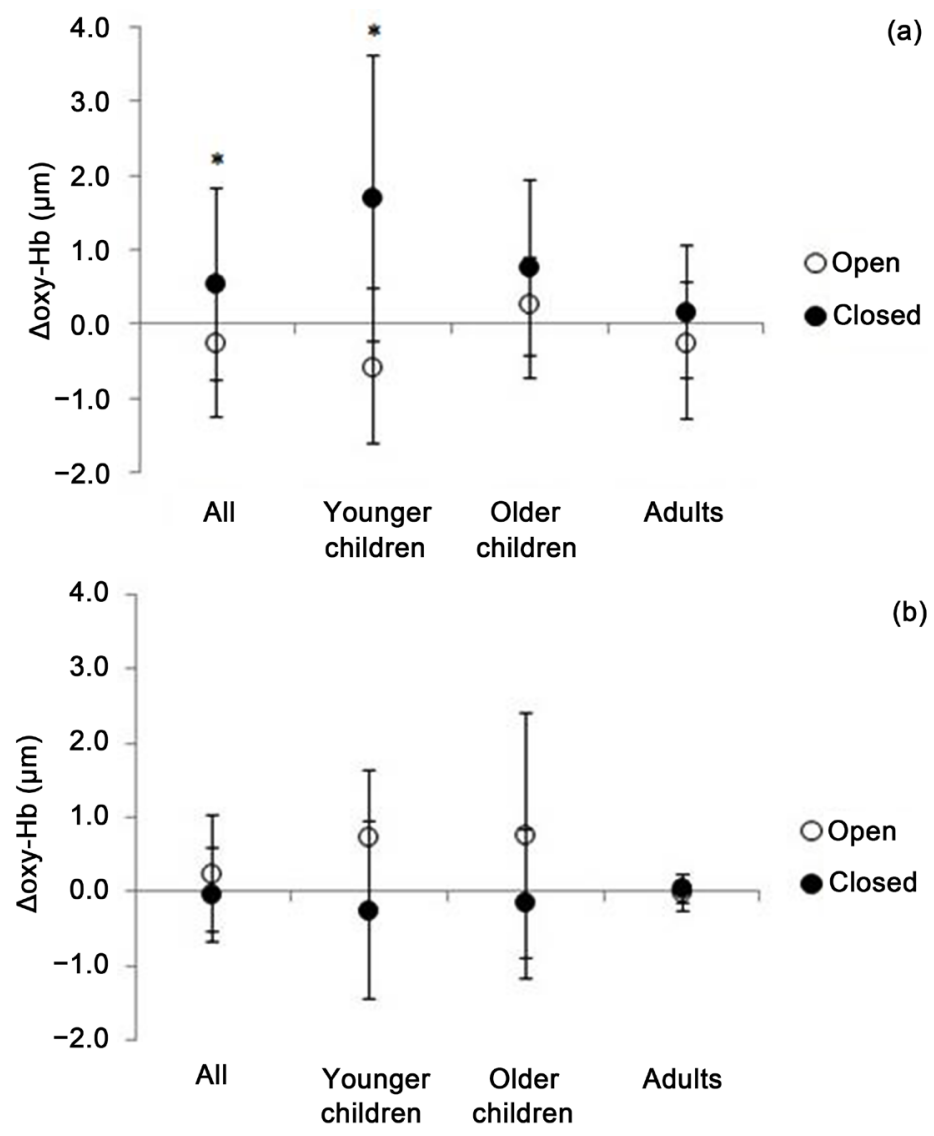

Figure 2. Relative changes in concentrations of a) oxy- $\mathrm{Hb}$ and b) deoxy- $\mathrm{Hb}$ in all groups combined and each age group during eyes open and eyes closed conditions (bars represent standard deviation). ${ }^{*}$ indicates significant differences at the .05 level. 
The PFC plays a key role in executive functions. It is also part of the default mode network (DMN) that activates during resting states and deactivates when performing goal-oriented tasks [42]. One function of the $\mathrm{DMN}$ is to monitor the external environment and prepare for unexpected future events. The DMN supports a broad low-level focus of attention of the external world during resting state by continuously gathering information and reallocating attention to previously unattended input as needed [16]. The results of our study showed that activity in the PFC during resting was higher in eyes closed condition compared to eyes open condition. Although eyes open with fixation is regarded as a passive fixation task which requires minimum mental efforts, the transition from eyes closed to eyes open resulted in a decrease of the activity in the PFC, which was similar to task-induced deactivation seen in the DMN. It is possible that the DMN has a higher activity and processes more information when individuals close their eyes rather than keep their eyes open.

The eyes closed condition has been used in most of the functional connectivity studies in the DMN using fNIRS [20] [43] [44]. However, the rationale of the selection of testing condition was not provided in those studies. Our results support their choices with using eyes closed condition. The greater activity of the DMN in the PFC during eyes closed condition indicates that more information related to the DMN may be available if researchers use eyes closed condition for data collection. On the other hand, a higher activity during baseline condition such as resting with eyes closed may interfere with the interpretation of task-induced activations. It is easy to identify task-induced activation if baseline condition has zero or minimum activation. Increases of activation found in task conditions can be attributed to mental efforts toward the requested tasks. With certain amount of activity in baseline condition, it is harder to differentiate task-induced activity from baseline activity. Theoretically, activation found in the DMN decreases during goal-oriented tasks. However, reductions of deactivation in the DMN have been reported in specific populations such as individuals with ASD and their unaffected siblings [22] [45]. Activation seen in task conditions can be a summation of task-induced activation and the residuals of the DMN that lack deactivation. Therefore, a baseline condition with eyes open, which has a lower activation, may be a better choice in order to minimize the effects of the activation found in resting state.

When comparing differences between eyes open and eyes closed conditions, a significant difference was found only in younger children but not older children or adults. The result indicated that the activity in the PFC in response to the transition between eyes open and eyes closed was age-dependent. To our knowledge, the current study was the first one to examine developmental changes in activity of the PFC between eyes open and eyes closed resting conditions. However, a previous study has reported agedependent responses in the PFC when participants reacted to an emotional stimulus. Todd and colleagues [46] found a greater response in the left frontal regions when participants processed an emotional stimulus in younger children compared to an inhibition task while no difference was found between responses of an emotional stimulus and the inhibition task in adults. In addition to different patterns of responsiveness to 
an emotional stimulus in the PFC, event-related activations in the PFC to visual stimulation has been observed in an infant's brain which implies that the PFC may playa role in processing visual signals [47]. Our results showed different activation patterns in the $\mathrm{PFC}$ in response to visual stimulation, i.e. transition between eyes closed and eyes open, which suggested that the PFC contributed to processing of visual information, especially in younger children.

The differences between eyes open and eyes closed conditions in all groups were observed in $\Delta \mathrm{oxy}-\mathrm{Hb}$ but not $\Delta$ deoxy-Hb in our study which suggested that $\Delta \mathrm{oxy}-\mathrm{Hb}$ is a more sensitive parameter to regional cerebral blood flow. This outcome was in accordance with previous findings that regional brain activation is always accompanied by increases in $\Delta \mathrm{oxy}-\mathrm{Hb}$ [48]. Regional brain activation requires glucose and oxygen consumption. The reduction of glucose and oxygenation results in increased blood flow to the region. The increased oxygen supply usually exceeds regional oxygen demands, resulting in increased oxygenation in the area [32] [49] [50]. An increase in oxygenation is presented in two patterns: 1) with an increase in total hemoglobin ( $\mathrm{HbT}$ ), and 2) with no changes in $\mathrm{HbT}$ [51]. In pattern one, an increase of $\Delta \mathrm{oxy}-\mathrm{Hb}$ with an increase or no changes in $\Delta$ deoxy- $\mathrm{Hb}$ are observed with increases in $\mathrm{HbT}$. In pattern two, increases in $\Delta$ oxy-Hb with reciprocal decreases in $\Delta$ deoxy- $\mathrm{Hb}$ are observed with no changes in $\mathrm{HbT}$. While increases in $\Delta \mathrm{oxy}-\mathrm{Hb}$ are always observed in activated areas, $\Delta$ deoxy- $\mathrm{Hb}$ can be increasing, decreasing, or present with no changes [48]. Strangman and colleagues found a stronger correlation between blood-oxygenation level-dependent signal obtained by fMRI and concentration changes in $\triangle$ oxy-Hb acquired by fNIRS [52]. Correlation between concentration changes in $\Delta$ deoxy- $\mathrm{Hb}$ and event-related activation is weaker and less consistent [25]. Our results were matched with previous studies that $\Delta \mathrm{oxy}-\mathrm{Hb}$ provided a more meaningful finding than $\Delta$ deoxy- $\mathrm{Hb}$. It suggested $\Delta \mathrm{oxy}-\mathrm{Hb}$ was a more sensitive outcome variable in fNIRS measurement for DMN and resting conditions assessments.

\section{Limitations}

Our results showed a significantly higher activation during eyes closed condition compared to eyes open condition when all groups were combined. When comparing $\Delta$ oxy$\mathrm{Hb}$ between eye conditions in each group, significant differences were found in only the younger children. The same trend that a higher activation during eyes closed condition compared to eyes open condition was seen in both older children and adults. There were no prior data available to calculate effect size and power. Therefore, statistical power was limited with a low number of participants in older children and adult groups. It may be a reason for the not detecting differences between the conditions for the various groups. Given that the DMN differentiates between resting conditions and task or goal-oriented conditions, it may be important to include an attention demanding task (e.g., Stroop) or working memory task (e.g., Tower of Hanoi) along with the resting conditions to further differentiate the contributions of the PFC during the eyes open and eyes closed conditions prior to different task demands. 


\section{Conclusions and Future Directions}

Resting state is a commonly used baseline condition in the study of brain activity during goal-oriented tasks. The selection of a baseline activity is critical to interpretation of task-induced activity. Our results showed that eyes open condition with a lower activity in the PFC might be a better baseline condition compared to eyes closed condition for executive-function tasks.

Medial PFC is part of the Default Mode Network (DMN), which activates during resting states. It is believed that the DMN helps an individual monitor the environment and prepare for an unpredicted future event. The higher activity in the PFC in the eyes closed condition may be related to the DMN. Regional activations in the PFC, e.g. medial PFC versus lateral PFC, should be investigated to explore the function of DMN in different age groups. In addition to developmental changes of the DMN, we will examine development of the PFC functions by comparing the neuronal activity during executive function tasks to that during the resting state with eyes open.

\section{References}

[1] Cooper, R.J., Selb, J., Gagnon, L., Phillip, D., Schytz, H.W., Iversen, H.K., Ashina, M. and Boas, D.A. (2012) A Systematic Comparison of Motion Artifact Correction Techniques for Functional Near-Infrared Spectroscopy. Frontiers in Neuroscience, 6, 147. http://dx.doi.org/10.3389/fnins.2012.00147

[2] Lloyd-Fox, S., Blasi, A. and Elwell, C.E. (2010) Illuminating the Developing Brain: The Past, Present and Future of Functional Near Infrared Spectroscopy. Neuroscience \& Biobehavioral Reviews, 34, 269-284. http://dx.doi.org/10.1016/j.neubiorev.2009.07.008

[3] Robertson, F.C., Douglas, T.S. and Meintjes, E.M. (2010) Motion Artifact Removal for Functional Near Infrared Spectroscopy: A Comparison of Methods. IEEE Transactions on Biomedical Engineering, 57, 1377-1387. http://dx.doi.org/10.1109/TBME.2009.2038667

[4] Sweeney, K.T., Ayaz, H., Ward, T.E., Izzetoglu, M., McLoone, S.F. and Onaral, B. (2011) A Methodology for Validating Artifact Removal Techniques for fNIRS. 2011 Annual International Conference of the IEEE Engineering in Medicine and Biology Society, Boston, 30 August-3 September 2011, 4943-4946. http://dx.doi.org/10.1109/IEMBS.2011.6091225

[5] Horecker, B.L. (1943) The Absorption Spectra of Hemoglobin and Its Derivatives in the Visible and Near Infrared Regions. Journal of Biological Chemistry, 148, 173-183.

[6] Wu, L., Eichele, T. and Calhoun, V.D. (2010) Reactivity of Hemodynamic Responses and Functional Connectivity to Different States of Alpha Synchrony: A Concurrent EEG-fMRI Study. Neuroimage, 52, 1252-1260. http://dx.doi.org/10.1016/j.neuroimage.2010.05.053

[7] Yang, L., Liu, Z. and He, B. (2010) EEG-fMRI Reciprocal Functional Neuroimaging. Clinical Neurophysiology, 121, 1240-1250. http://dx.doi.org/10.1016/j.clinph.2010.02.153

[8] Barry, R.J., Clarke, A.R., Johnstone, S.J. and Brown, C.R. (2009) EEG Differences in Children between Eyes-Closed and eyes-Open Resting Conditions. Clinical Neurophysiology, 120, 1806-1811. http://dx.doi.org/10.1016/j.clinph.2009.08.006

[9] Barry, R.J., Clarke, A.R., Johnstone, S.J., Magee, C.A. and Rushby, J.A. (2007) EEG Differences between Eyes-Closed and Eyes-Open Resting Conditions. Clinical Neurophysiology, 118, 2765-2773. http://dx.doi.org/10.1016/j.clinph.2007.07.028

[10] McAvoy, M., Larson-Prior, L., Nolan, T.S., Vaishnavi, S.N., Raichle, M.E. and d'Avossa, G. 
(2008) Resting States Affect Spontaneous BOLD Oscillations in Sensory and Paralimbic Cortex. Journal of Neurophysiology, 100, 922-931. http://dx.doi.org/10.1152/jn.90426.2008

[11] Van Dijk, K.R.A., Hedden, T., Venkataraman, A., Evans, K.C., Lazar, S.W. and Buckner, R.L. (2010) Intrinsic Functional Connectivity as a Tool for Human Connectomics: Theory, Properties, and Optimization. Journal of Neurophysiology, 103, 297-321. http://dx.doi.org/10.1152/jn.00783.2009

[12] Yan, C.G., Liu, D.Q., He, Y., Zou, Q.H., Zhu, C.Z., Zuo, X.N., Long, X.Y. and Zang, Y.F. (2009) Spontaneous Brain Activity in the Default Mode Network Is Sensitive to Different Resting-State Conditions with Limited Cognitive Load. PLoS ONE, 4, e5743. http://dx.doi.org/10.1371/journal.pone.0005743

[13] Zou, Q., Long, X., Zuo, X., Yan, C., Zhu, C., Yang, Y., Liu, D., He, Y. and Zang, Y. (2009) Functional Connectivity between the Thalamus and Visual Cortex under Eyes Closed and Eyes Open Conditions: A Resting-State fMRI Study. Human Brain Mapping, 30, 3066-3078. http://dx.doi.org/10.1002/hbm.20728

[14] Merzagora, A., Ayaz, H., Izzetoglu, M., Onaral, B. and Shewokis, P.A. (2009) fNIR Study of Prefrontal Cortex Activity during Eyes-Open and Eyes-Closed Conditions. Neuroimage, 47, S142. http://dx.doi.org/10.1016/S1053-8119(09)71416-8

[15] Riera, J.J., Schousboe, A., Waagepetersen, H.S., Howarth, C. and Hyder, F. (2008) The Micro-Architecture of the Cerebral Cortex: Functional Neuroimaging Models and Metabolism. Neuroimage, 40, 1436-1459. http://dx.doi.org/10.1016/j.neuroimage.2007.12.051

[16] Gusnard, D.A. and Raichle, M.E. (2001) Searching for a Baseline: Functional Imaging and the Resting Human Brain. Nature Reviews Neuroscience, 2, 685-694.

http://dx.doi.org/10.1038/35094500

[17] Kelley, W.M., Macrae, C.N., Wyland, C.L., Caglar, S., Inati, S. and Heatherton, T.F. (2002) Finding the Self? An Event-Related fMRI Study. Journal of Cognitive Neuroscience, 14, 785-794. http://dx.doi.org/10.1162/08989290260138672

[18] Mitchell, J.P., Macrae, C.N. and Banaji, M.R. (2006) Dissociable Medial Prefrontal Contributions to Judgments of Similar and Dissimilar Others. Neuron, 50, 655-663.

http://dx.doi.org/10.1016/j.neuron.2006.03.040

[19] Bonnelle, V., Leech, R., Kinnunen, K.M., Ham, T.E., Beckmann, C.F., De Boissezon, X., Greenwood, R.J. and Sharp, D.J. (2011) Default Mode Network Connectivity Predicts Sustained Attention Deficits after Traumatic Brain Injury. Journal of Neuroscience, 31, 1344213451. http://dx.doi.org/10.1523/JNEUROSCI.1163-11.2011

[20] Duan, X., Liao, W., Liang, D., Qiu, L., Gao, Q., Liu, C., Gong, Q. and Chen, H. (2012) Large-Scale Brain Networks in Board Game Experts: Insights from a Domain-Related Task and Task-Free Resting State. PLoS ONE, 7, e32532.

http://dx.doi.org/10.1371/journal.pone.0032532

[21] Griebling, J., Minshew, N.J., Bodner, K., Libove, R., Bansal, R., Konasale, P., Keshavan, M.S. and Hardan, A. (2010) Dorsolateral Prefrontal Cortex Magnetic Resonance Imaging Measurements and Cognitive Performance in Autism. Journal Child Neurology, 25, 856-863. http://dx.doi.org/10.1177/0883073809351313

[22] Kennedy, D.P., Redcay, E. and Courchesne, E. (2006) Failing to Deactivate: Resting Functional Abnormalities in Autism. Proceedings of the National Academy Sciences of the United States of America, 103, 8275-8280. http://dx.doi.org/10.1073/pnas.0600674103

[23] Raichle, M.E. (2006) Neuroscience. The Brain’s Dark Energy. Science, 314, 1249-1250. http://dx.doi.org/10.1126/science. 1134405

[24] Stevens, M.C., Kiehl, K.A., Pearlson, G.D. and Calhoun, V.D. (2009) Brain Network Dy- 
namics during Error Commission. Human Brain Mapping, 30, 24-37. http://dx.doi.org/10.1002/hbm.20478

[25] Ehlis, A.C., Herrmann, M.J., Plichta, M.M. and Fallgatter, A.J. (2007) Cortical Activation during Two Verbal Fluency Tasks in Schizophrenic Patients and Healthy Controls as Assessed by Multi-Channel Near-Infrared Spectroscopy. Psychiatry Research: Neuroimaging, 156, 1-13.http://dx.doi.org/10.1016/j.pscychresns.2006.11.007

[26] Takizawa, R., Kasai, K., Kawakubo, Y., Marumo, K., Kawasaki, S., Yamasue, H. and Fukuda, M. (2008) Reduced Frontopolar Activation during Verbal Fluency Task in Schizophrenia: A Multi-Channel Near-Infrared Spectroscopy Study. Schizophrenia Research, 99, 250262.http://dx.doi.org/10.1016/j.schres.2007.10.025

[27] MacDonald, A.W., Cohen, J.D., Stenger, V.A. and Carter, C.S. (2000) Dissociating the Role of the Dorsolateral Prefrontal and Anterior Cingulate Cortex in Cognitive Control. Science, 288, 1835-1838. http://dx.doi.org/10.1126/science.288.5472.1835

[28] Schroeter, M.L., Zysset, S., Wahl, M. and von Cramon, D.Y. (2004) Prefrontal Activation due to Stroop Interference Increases during Development-An Event-Related fNIRS Study. Neuroimage, 23, 1317-1325. http://dx.doi.org/10.1016/j.neuroimage.2004.08.001

[29] Abraham, A., Thybusch, K., Pieritz, K. and Hermann, C. (2014) Gender Differences in Creative Thinking: Behavioral and fMRI Findings. Brain Imaging Behavior, 8, 39-51. http://dx.doi.org/10.1007/s11682-013-9241-4

[30] Koike, S., Takizawa, R., Nishimura, Y., Kinou, M., Kawasaki, S. and Kasai, K. (2013) Reduced but Broader Prefrontal Activity in Patients with Schizophrenia during $N$-Back Working Memory Tasks: A Multi-Channel Near-Infrared Spectroscopy Study. Journal of Psychiatric Research, 47, 1240-1246. http://dx.doi.org/10.1016/j.jpsychires.2013.05.009

[31] Griffiths, S.T., Gundersen, H., Neto, E., Elgen, I., Markestad, T., Aukland, S.M. and Hugdahl, K. (2013) FMRI: Blood Oxygen Level-Dependent Activation during a Working Memory-Selective Attention Task in Children Born Extremely Preterm. Pediatric Research, 74, 196-205. http://dx.doi.org/10.1038/pr.2013.79

[32] Obrig, H. and Villringer, A. (2003) Beyond the Visible-Imaging the Human Brain with Light. Journal of Cerebral Blood Flow \& Metabolism, 23, 1-18. http://dx.doi.org/10.1097/01.WCB.0000043472.45775.29

[33] Homan, R.W., Herman, J. and Purdy, P. (1987) Cerebral Location of International 10-20 System Electrode Placement. Electroencephalography and Clinical Neurophysiology, 66, 376-382. http://dx.doi.org/10.1016/0013-4694(87)90206-9

[34] Okamoto, M., Dan, H., Sakamoto, K., Takeo, K., Shimizu, K., Kohno, S., Oda, I., Isobe, S., Suzuki, T., Kohyama, K. and Dan, I. (2004) Three-Dimensional Probabilistic Anatomical Cranio-Cerebral Correlation via the International 10-20 System Oriented for Transcranial Functional Brain Mapping. Neuroimage, 21, 99-111. http://dx.doi.org/10.1016/j.neuroimage.2003.08.026

[35] Delpy, D.T., Cope, M., van der Zee, P., Arridge, S., Wray, S. and Wyatt, J. (1988) Estimation of Optical Pathlength through Tissue from Direct Time of Flight Measurement. Physics in Medicine and Biology, 33, 1433-1442. http://dx.doi.org/10.1088/0031-9155/33/12/008

[36] Villringer, A. and Chance, B. (1997) Non-Invasive Optical Spectroscopy and Imaging of Human Brain Function. Trends in Neurosciences, 20, 435-442. http://dx.doi.org/10.1016/S0166-2236(97)01132-6

[37] Ayaz, H., Shewokis, P.A., Curtin, A., Izzetoglu, M., Izzetoglu, K. and Onaral, B. (2011) Using Maze Suite and functional near Infrared Spectroscopy to Study Learning in Spatial Navigation. Journal of Visualized Experiments, No. 56, e3443. 
[38] Izzetoglu, M., Bunce, S.C., Izzetoglu, K., Onaral, B. and Pourrezaei, K. (2007) Functional Brain Imaging Using Near-Infrared Technology. IEEE Engineering in Medicine and Biology Magazine, 26, 38-46. http://dx.doi.org/10.1109/MEMB.2007.384094

[39] Lin, P.Y., Lin, S.I. and Chen, J.J. (2012) Functional near Infrared Spectroscopy Study of Age-Related Difference in Cortical Activation Patterns during Cycling with Speed Feedback. IEEE Transactions on Neural Systems and Rehabilitation Engineering, 20, 78-84. http://dx.doi.org/10.1109/TNSRE.2011.2170181

[40] Huppert, T.J., Diamond, S.G., Franceschini, M.A. and Boas, D.A. (2009) HomER: A Review of Time-Series Analysis Methods for Near-Infrared Spectroscopy of the Brain. Applied Optics, 48, D280-D298. http://dx.doi.org/10.1364/AO.48.00D280

[41] Van Selst, M. and Jolicoeur, P. (1994) A Solution to the Effect of Sample Size on Outlier Elimination. Quarterly Journal of Experimental Psychology Section A-Human Experimental Psychology, 47, 631-650. http://dx.doi.org/10.1080/14640749408401131

[42] Raichle, M.E., MacLeod, A.M., Snyder, A.Z., Powers, W.J., Gusnard, D.A. and Shulman, G.L. (2001) A Default Mode of Brain Function. Proceedings of the National Academy Sciences of the United States of America, 98, 676-682. http://dx.doi.org/10.1073/pnas.98.2.676

[43] Lu, C.M., Zhang, Y.J., Biswal, B.B., Zang, Y.F., Peng, D.L. and Zhu, C.Z. (2010) Use of fNIRS to Assess Resting State Functional Connectivity. Journal of Neuroscience Methods, 186, 242-249. http://dx.doi.org/10.1016/j.jneumeth.2009.11.010

[44] Zhang, H., Zhang, Y.J., Lu, C.M., Ma, S.Y., Zang, Y.F. and Zhu, C.Z. (2010) Functional Connectivity as Revealed by Independent Component Analysis of Resting-State fNIRS Measurements. Neuroimage, 51, 1150-1161. http://dx.doi.org/10.1016/j.neuroimage.2010.02.080

[45] Spencer, M.D., Chura, L.R., Holt, R.J., Suckling, J., Calder, A.J., Bullmore, E.T. and Baron-Cohen, S. (2012) Failure to Deactivate the Default Mode Network Indicates a Possible Endophenotype of Autism. Molecular Autism, 3, 15. http://dx.doi.org/10.1186/2040-2392-3-15

[46] Todd, R.M., Lee, W., Evans, J.W., Lewis, M.D. and Taylor, M.J. (2012) Withholding Response in the Face of a Smile: Age-Related Differences in Prefrontal Sensitivity to Nogo Cues Following Happy and Angry Faces. Developmental Cognitive Neuroscience, 2, 340350.http://dx.doi.org/10.1016/j.dcn.2012.01.004

[47] Taga, G., Asakawa, K., Hirasawa, K. and Konishi, Y. (2003) Hemodynamic Responses to Visual Stimulation in Occipital and Frontal Cortex of Newborn Infants: A Near-Infrared Optical Topography Study. Early Human Development, 75, S203-S210. http://dx.doi.org/10.1016/j.earlhumdev.2003.08.023

[48] Hoshi, Y. (2003) Functional Near-Infrared Optical Imaging: Utility and Limitations in Human Brain Mapping. Psychophysiology, 40, 511-520.

http://dx.doi.org/10.1111/1469-8986.00053

[49] Fox, P.T., Raichle, M.E., Mintun, M.A. and Dence, C. (1988) Nonoxidative Glucose Consumption during Focal Physiologic Neural Activity. Science, 241, 462-464. http://dx.doi.org/10.1126/science.3260686

[50] Malonek, D. and Grinvald, A. (1996) Interactions between Electrical Activity and Cortical Microcirculation Revealed by Imaging Spectroscopy: Implications for Functional Brain Mapping. Science, 272, 551-554. http://dx.doi.org/10.1126/science.272.5261.551

[51] Hoshi, Y. and Tamura, M. (1997) Fluctuations in the Cerebral Oxygenation State during the Resting Period in Functional Mapping Studies of the Human Brain. Medical \& Biologi- 
cal Engineering Computing, 35, 328-330. http://dx.doi.org/10.1007/BF02534085

[52] Strangman, G., Culver, J.P., Thompson, J.H. and Boas, D.A. (2002) A Quantitative Comparison of Simultaneous BOLD fMRI and NIRS Recordings during Functional Brain Activation. NeuroImage, 17, 719-731. http://dx.doi.org/10.1006/nimg.2002.1227

\section{Submit or recommend next manuscript to SCIRP and we will provide best service} for you:

Accepting pre-submission inquiries through Email, Facebook, LinkedIn, Twitter, etc. A wide selection of journals (inclusive of 9 subjects, more than 200 journals)

Providing 24-hour high-quality service

User-friendly online submission system

Fair and swift peer-review system

Efficient typesetting and proofreading procedure

Display of the result of downloads and visits, as well as the number of cited articles

Maximum dissemination of your research work

Submit your manuscript at: http://papersubmission.scirp.org/

Or contact jbbs@scirp.org 